\title{
Colina do Horto: Observando e Aprendendo com o Meio Ambiente
}

Francisca Ilka Oliveira Bezerra da Costa ${ }^{1}$; Theóphilo Michel Álvares Cabral Beserra ${ }^{2}$

Resumo: O presente estudo constituiu-se numa revisão bibliográfica enfocando a Colina do Horto do Geopark Araripe, objetivando discutir aspectos históricos, humanos, sociais, econômicos, políticos e geológicos. Traça caminhos que conduzem o leitor à compreensão da importância deste Geossítio para o desenvolvimento de Juazeiro do Norte, Ceará. Deve-se afirmar que, através das observações e pesquisas realizadas sobre o tema, constatou-se que o mesmo continua contribuindo para o crescimento da cidade, respeitando e zelando pelo meio ambiente.

Palavra Chave: Colina do Horto. Meio ambiente. Juazeiro do Norte.

\section{Hill from the Horto: Watching and Learning with The Environment}

\begin{abstract}
This study consisted of a literature review focusing on the Hill from the Horto in Araripe Geopark, aiming to discuss historical, human, social, economic, political and geological. Moth paths that lead the reader to understand the importance of this Geosite for the development of Juazeiro do Norte, Ceará. It must be said that, through observations and research on the subject, it was found that it continues to contribute to the growth of the city, respecting and caring for the environment.
\end{abstract}

Keyword: Hill from the Horto. Environment. Juazeiro do Norte.

\section{Introdução}

As sociedades humanas desde o seu limiar vivem uma busca intensa de sua afirmação seja de maneira coletiva, através da tentativa de conseguir hegemonia sobre outras sociedades, por exemplo, por meio de guerras, seja de maneira individual onde o indivíduo planeja sua autoafirmação tentando sobrepor-se aos demais em qualquer área, ou quaisquer áreas, dentro do contexto sociocultural no qual o mesmo esteja inserido - política, religião, economia, arte etc.

\footnotetext{
${ }^{1}$ Mestranda em Educação - Programa de Mestrado Internacional em Educação Anne Sullivan University - francisca_ilka@ @otmal.com;

${ }^{2}$ Mestre em Geografia pela Universidade Federal do Ceará, Especialista em Geografia e Meio Ambiente pela Universidade Regional do Cariri, licenciado em geografia pela Universidade Regional do Cariri. Atualmente é membro do Conselho Municipal de Defesa do Meio Ambiente de Juazeiro do Norte - Ceará - COMDEMA, membro do Comitê Institucional de Avaliação do Programa de Bolsas de Iniciação Científica e Tecnológica do Instituto CENTEC, Conselheiro do Eixo Tecnológico Ambiente e Saúde da Faculdade de Tecnologia CENTEC, FATEC-CARIRI, membro do Núcleo Docente Estruturante do Eixo Tecnológico Ambiente e Saúde e representante docente eleito para o Conselho de Administração do Instituto CENTEC junto a Secretaria da Ciência, Tecnologia e Educação Superior do Estado do Ceará SECITECE. Professor do eixo tecnológico ambiente e saúde. E-mail: mic.beserra@ hotmail.com.
} 
Id on Line Revista Multidisciplinar e de Psicologia

Id on Line Multidisciplinary Journal and Psycology

\section{A Colina do Horto em Juazeiro do Norte - CE}

\section{Características}

O Geossítio Colina do Horto está localizado a 3km da cidade de Juazeiro do Norte, é composta de um Museu Vivo do Padre Cícero, a estátua do Padre Cícero, a Igreja de Bom Jesus do Horto e a trilha de acesso ao Santo Sepulcro (2600 metros).

O Santo Sepulcro é o local onde os Romeiros fazem suas romarias pagando promessas acendendo velas, existem no local duas capelinhas onde se encontra enterrado um dos beatos que viveu na época do Padre Cícero. A colina do Horto está localizada na zona urbana, no município de Juazeiro, é um dos pontos turísticos mais importantes da cidade; é um cartão postal, do alto da colina você tem uma visão de toda cidade de Juazeiro, da Chapada do Araripe entre outros.

Para a compreensão de um melhor aprendizado sobre o Geossítio Colina do Horto sobre o processo histórico e religioso, não se pode esquecer da influência do Padre Cícero Romão Batista, considerado a maior figura religiosa e política do final do século XIX e início do século XX que contribuiu muito em todos os aspectos para o crescimento do município de Juazeiro do Norte. Onde quem vai ao município jamais deixará de visitar em primeiro lugar a estátua do Padre Cícero, a trilha do Santo Sepulcro, muro da sedição de 1914.

\section{A Nova Jerusalém}

As cidades como Barbalha, Missão Velha, Milagres, Aurora, e principalmente Crato, erma dominadas pelo Coronelismo que fazia pactos oligárquicos. O Padre Cícero influenciou no desenvolvimento econômico com cultivo e na produção de maniçoba e algodão que eram exportados para o mercado internacional.

Percebe-se que desde o final do século XIX Juazeiro conhecido como nova Jerusalém era considerada como uma cidade sagrada então devido a isso, foram grandes o contingente de pessoas com novos interesses e de diferentes classes sociais que vinham a procura de abrigo, e também de receber conselhos do Padre Cícero, muitas vezes trabalhavam lavou e mão de obra não era muito valorizada. 
Devido ao crescimento do comercio além da ambição religiosa do Padre Cícero a cidade começou a reivindicar a sua emancipação política a qual estava ligada ao Crato. Não entraram em acordo então a política ficou dividida entre os Coronéis da região.

Floro Bartolomeu que tinha influência política na região, atraiu a confiança do Padre Cícero em 1911, Bartolomeu criou os pactos dos Coronéis.

Entre as cláusulas constava:

a) Decisão dos integrantes de não apoiar deposição na região;

b) O desejo de fortalecer as pessoas e políticos da região;

c) Manter a lealdade incondicional a Antônio Nogueira Acioli, presidente do estado e líder da família que dominava a política no Ceará desde o final do Século XIX.

Juazeiro foi conhecido como vila, sede do município. Houve um movimento contra o partido de Acioli que faziam parte os profissionais liberais, de soldados oficiais do exército e mais de 20 mil pessoas, u movimento que ocorreu em Fortaleza em dezembro de 1911 a janeiro de 1912.

Acióli revoltado com a situação colocou soldados e jagunços contra a manifestação, contra seu partido, com isso só aumentou a revolta do outro partido.

Em 24 de Janeiro de 1912, o oligarca foi exilado a capital Federal, com sua ausência fortaleceu o candidato de oposição ao governo, Coronel Franco Rabelo. Então as capitaneadas eram derrubadas no Nordeste.

A eleição do Coronel Franco Rabelo para presidente do Ceará em meados de 1912 fez ruir as bases do pacto firmado do Cariri.

Houve uma revolta entre Crato e Juazeiro onde os policiais prenderam alguns jagunços acusados de bandidos, todos ligados a oposição ao político de farda, além disso houve um confronto direto com Padre Cícero ao destruir homens de sua confiança de cargos públicos e acusá-los de abrigar bandidos em Juazeiro.

\section{Sedição de Juazeiro}

Foi um confronto ocorrido no ano de 1914 entre o governo federal e as oligarquias cearenses, envolvendo o Padre Cícero Romão Batista. 
No dia 12 de dezembro de 1913 houve uma assembleia composta por deputados oposicionistas que declarou a ilegalidade do governo de Franco Rabelo. Foi nomeado Floro Bartolomeu como presidente provisório.

Rabelo deu a resposta imediata pois no dia 15 de dezembro, as tropas estaduais estavam estacionadas no Crato, comandada por Ladislau Lourenço onde foram invadir Juazeiro no dia 20, as tropas do governo tinham afrente o Coronel Alípio Lopes, escolhido por Rabelo para dar fim a sedição.

Embora Juazeiro tenha sofrido muita tenção, resistência dos fieis do Padre Cícero, aliado ao ataque dos cangaceiros reunidos por Floro Bartolomeu, conseguiu êxito nessa batalha. Cercada por tropas rebeldes, a cidade santa enfrentou a fome e a falta de munição.

Apesar dos obstáculos a tropa que entoava cânticos em louvor de Padre Cícero conseguiu resistir e contra-atacar. Graças a essa ofensa, no dia 24 de janeiro de 1944 Crato foi ocupada por homens comandados por Bartolomeu. Depois que tomaram Barbalha, as cidades foram pilhadas e com espólio Juazeiro pode se recompor da escassez de viveres e de munição que se encontravam desde os ataques das forças rebeldes.

Em marcha e pela estrada de ferro seguiram a pé os sedioses, como eram conhecidos, ocuparam Miguel Calmom, Senador Pompeu, Quixeramobim, foram até Fortaleza, a 19 de março de 1914.

Foi concluída a revolução de Juazeiro, como troféu, a Nova Jerusalém foi elevada a categoria de cidade no dia 23 de julho do mesmo ano e Padre Cicero Romão Batista foi consagrado em dos mais proeminentes Coronéis da política republicada do pais.

\section{Depois da Sedição de Juazeiro}

Pode-se dizer que o Padre Cícero teve uma grande relevância na história do município como líder religioso, político, ocupando o cargo de prefeito durante quinze anos, participou diretamente a sedição de Juazeiro no ano de 1914, onde o município foi emancipado da cidade do Crato. Depois da luta política entre os Coronéis as Oligarquias e Acioli ele ganhou mais prestigio na história não só do Juazeiro, mas também do Cerará. 
O Padre Cicero teve grande repercussão no Nordeste e no Brasil devido um fato que se passou no Município.

Constatou-se segundo a História que em uma missa na Igreja celebrada pelo mesmo a hóstia consagrada transformou-se em sangue na boca da Beata Maria de Araújo. Os fieis acreditavam que teria sido um suposto "milagre". A Igreja Católica considerou como místico e o sacerdote foi proibido de exercer sua função como sacerdócio. O mesmo em 1898 viajou para Roma conseguindo sua absolvição do Papa Leão XIII, mesmo assim continuou proibido de fazer suas celebrações. Padre Cicero morreu no ano de 1934, se destacou como uma das principais figuras da história do pais.

Hoje, o túmulo do Pare Cicero é considerado o mais importante, e o mais visitado do país pelos peregrinos que vêm de todos os lugares fazendo suas romarias e pagando suas promessas. Depois de muito tempo o Vaticano aceitou o pedido para reconciliação da Igreja Católica com o religioso para a CNBB, esse pode ser o primeiro passo para a beatificação.

Pode-se dizer que no decorrer de toda história não se sabe o que aconteceu sobre o suposto "milagre", se o fato é verdadeiro ou não, para os devotos acreditam que sim, mas existe os lados opostos a Igreja e a ciência que até hoje não se teve nenhuma resposta concreta.

\section{O Santo Sepulcro}

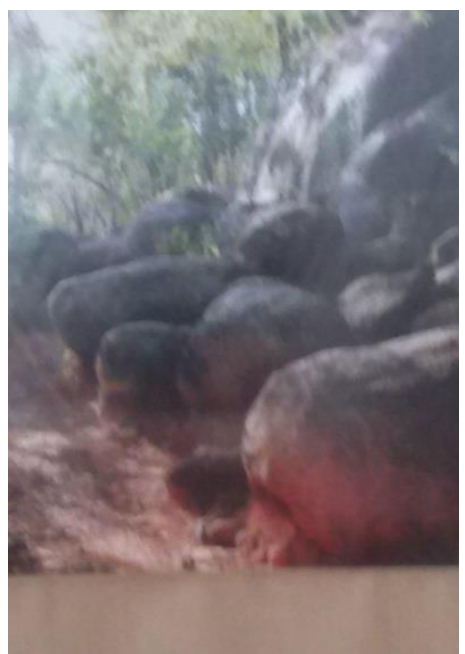

O Santo Sepulcro se encontra a $3 \mathrm{~km}$ do Horto localizado no município de Juazeiro do Norte. O mesmo não é um local de muito acesso. A romaria quando faz o percurso da trilha costumam levar pedras sobre a cabeça, fazendo penitência e pagando as promessas ou agradecendo por tudo que conseguiram nas conquistas, vitórias, e por todos os objetivos realizados.

Sempre quando chegam no local acima citado passam por uma fenda conhecida como "pedra do pecado", onde acredita-se que a alma pode ser purificada de acordo com as orações, isso é o que dizem as crenças populares. As rochas encontradas são blocos grandes de arenitos, que os visitantes e devotos aproveitam para fazer suas preces e também para descansarem. 
Os fiéis consideram o local como um lugar santo, o mesmo tem cruzeiros, entalhes em pedras que são consideradas sagradas e encantadas, marcado no passado pela presença de beatos e do Padre Cícero, todos os consideram como local de penitência e respeito, associam o túmulo onde Jesus foi sepultado.

Percebe-se o grande valor cultural que está presente no Geossítio Colina do Horto, o mesmo se associam as questões religiosas como também a geodiversidade que existe naquele local. São encontrados nos mesmo vários tipos de rochas como por exemplo: Igreas (granito), metamórficos (filito) sedimentares (arenito) onde são de primeira qualidade, onde são encontradas durante o percurso e uma oportunidade de conhecer de perto o ciclo das rochas.

Por possuir uma altitude bastante elevada, há alguns mirantes como o monumento do Padre Cicero, que permite visualizar as paisagens locais como a vegetação da caatinga, a Chapada do Araripe, a cidade do Juazeiro do Norte, Crato e Barbalha.

Constata-se que na trilha do Santo Sepulcro existem vários recursos naturais e são lembrados sempre os preceitos ecológicos do Padre Cícero e a recomendação de preservação do meio ambiente, pois o mesmo era pioneiro em assuntos relacionados ao meio ambiente.

\section{Preceitos de Padre Cícero}

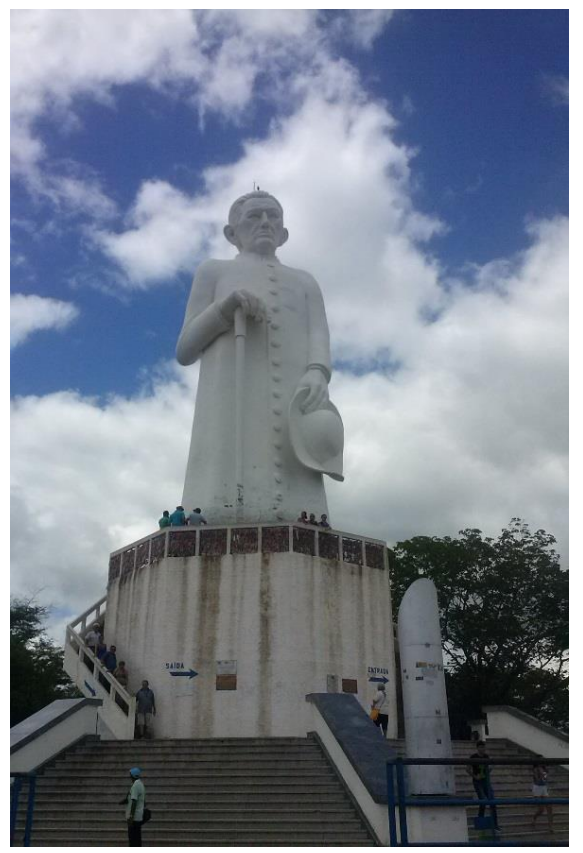

Dentre os princípios éticos, morais e religiosos, Padre Cícero Romão Batista deixa registrado seus conselhos para o povo sertanejo dentre os quais destacamse: "não derrubar o mato, nem mesmo um só pé de pau...; não tocar fogo no roçado nem na caatinga...; não caçar mais e deixar os bichos viverem...; não criar o boi nem o pode soltar...; faça cercados e deixe o pasto descansar para ele se refazer...; não plantar nos caminhos de água para que a chuva não arraste a terra e perca a sua riqueza...; construir uma cisterna no oitão de sua casa, para guardar água da chuva; represar os riachos de cem em cem metros, 
ainda que seja com pedra solta; plantar cada dia, pelo menos um pé de algaroba, caju, ou outra árvore qualquer, até que o sertão todo seja uma mata só...

Se o sertanejo obedecer estes preceitos a seca vai aos poucos se acabando, o gado vai melhorando e o povo terá sempre o que comer. Mas, se não obedecer dentro de vinte anos todo sertão será um deserto só. Percebe-se através da história a preocupação do Padre Cícero com o meio ambiente, o mesmo tinha uma visão de mundo sobre o assunto.

Pode-se dizer que há muito tempo os recursos naturais vêm sendo utilizados discriminadamente, principalmente nos dias atuais. Existem vários impactos e consequências causadas pelas ações dos homens de forma intensa.

Constata-se que é necessária uma tomada de consciência por parte do ser humano, quando tiver necessidade de mudar o modo de explorar os recursos naturais.

Para isso será necessária que se mude os hábitos e atitudes das pessoas que elas colocarem para o desenvolvimento voltado para a sustentabilidade.

Sabe-se que é de grande relevância a conscientização em relação ao meio ambiente que o homem se sinta sujeito histórico, ativo, critico, participativo e responsável pelo futuro do planeta.

\section{A Capela da Senhora Santana}

A Capela da Senhora Santana, se encontra no Santo Sepulcro, onde a mesma foi construída a mando do Padre Cícero, neste local onde os fiéis fortalecem sua fé e fazem a peregrinação.

No início do trajeto ainda é possível ver uma antiga muralha da guerra de XIV, ou então como é conhecida também sedição de Juazeiro, conflito que aconteceu entre os Coronéis, as oligarquias cearenses e o governo federal ocorrido em 1914. 


\section{Museu Vivo do Padre Cícero}

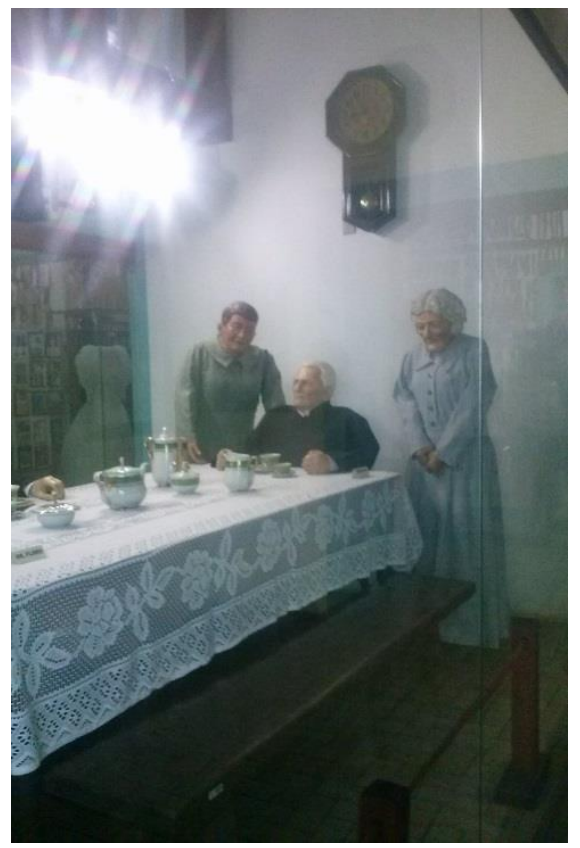

No Museu Vivo encontra-se imagens em momentos de descanso em salas, quartos e também uma quantidade enorme de mostras de ex-votos das promessas que foram alcançadas pelos seus devotos que foram alcançadas pelos seus devotos que fazem romarias, para pagarem as graças alcançadas, onde fazem suas homenagens, tem também as réplicas de pessoas da convivência diária do patriarca do Nordeste em tamanho natural. O museu foi feito no ano de 1999. Parece real que causa admiração a todos que o visitam.

Na sala de reuniões do Museu Vivo com o Padre Cicero se encontra a Beata Mocinha, que foi sua governanta da casa dele, Terezinha, a escrava branca que ficou liberta e passou a morar com ele depois que o pai do Padre Cicero assinou a carta de alforria, a mesma ficou conhecida como Terezinha do Padre Cicero. Também se encontra Floro Bartolomeu, que foi médico do mesmo e Deputado Federal e também Aureliano, o primeiro romeiro a chegar em Juazeiro do Norte, natural da cidade de Atalaia do Estado de Alagoas, foi quem trouxe o comércio para o município de Juazeiro.

A cena do Museu representa um jantar que o Padre Cicero deu na sua residência em 1918. Segundo a história nesse dito dia o Padre Cicero disse ao romeiro Aureliano: "Você vai ser pai de trinta e seis filhos", profecia que se concretizou no ano de 1956, com o nascimento de Francisco Gondim Pereira, último filho do seu quinto casamento.

Aureliano Pereira da Silva (1888-1973), veio com seus pais José Marcolino da Silva e Antônia Pereira da Silva, o mesmo era comerciante, construtor de dezenas de casas em várias ruas do Juazeiro, participou da emancipação política de Juazeiro, era devoto e fiel ao Padre Cícero se radicalizou em Juazeiro e contribuiu muito para o engrandecimento do município. 
Id on Line Revista Multidisciplinar e de Psicoloqia

Id on Line Multidisciplinary Journal and Psycology

\section{Estátua do Padre Cícero na Colina do Horto}

Local bastante visitado pelos peregrinos católicos, vindos de todo lugar do Nordeste, do Brasil e de alguns lugares de outros países. É um local de romarias, reflexões e muita fé, a estátua do Padre Cícero é um monumento que foi construído em homenagem ao Padre Cícero, situado na Zona Urbana de Juazeiro do Norte, onde se encontra também um pequeno Museu Vivo e uma Igreja. O projeto inicial previa que a estátua tivesse 7 metros de altura, então a mesma foi redimensionada e quem a construiu, a esculpiu com 27 metros de altura. $\mathrm{O}$ responsável pela obra foi Armando Lacerda, a estátua foi construída no ano 1969, sua inauguração foi no dia $1^{\circ}$ de novembro do mesmo ano, tendo como prefeito da época José Mauro Castelo Branco Sampaio. Rômulo Ayres Montenegro foi o engenheiro responsável pelos cálculos de engenharia da base e da estátua, trata-se de um dos pontos mais visitados do munícipio.

\section{O Milagre em Juazeiro}

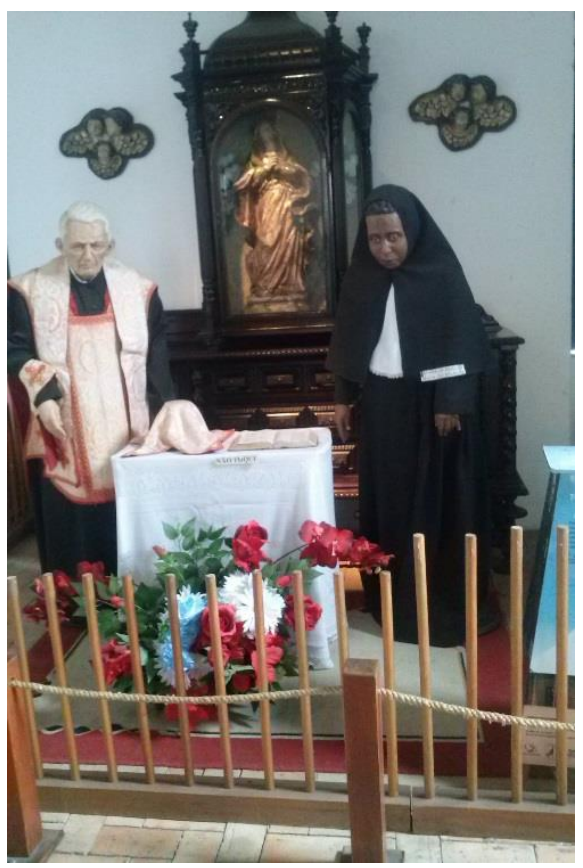

Na Sexta Feira Santa no dia 6 de março de 1889 aconteceu um fato inédito na Igreja Católica na cidade do município de Juazeiro do Norte, onde aconteceu a transformação da hóstia em sangue, quando a Beata Maria de Araújo recebeu a comunhão dada pelo Padre Cícero Romão Batista mediante várias pessoas. Este fenômeno ficou conhecido como "milagre em Juazeiro", fala-se que este fenômeno se repetiu durante quase dois anos seguidos, devido este acontecimento aumentou bastante o fluxo de romaria por motivos religiosos, principalmente de pessoas vindas do Nordeste dos estados de Alagoas, Pernambuco, Paraíba entre outros. 
A devoção pelo Padre Cícero continua atraindo uma das maiores romarias do Brasil, anualmente é grande a quantidade de romeiros e devotos do mesmo que vem pagar suas promessas.

Segundo a história existem três grandes romarias na cidade acima citadas, a das candeias, as de finados, e de Nossa Senhora das Dores, padroeira da cidade.

A primeira delas é a da Nossa Senhora das Dores realizadas no mês de setembro, comemorada com celebrações, novenas, missas, procissões de caminhões de romeiros, carroças enfeitadas transportando fieis e pessoas vindas de vários lugares do Brasil e algumas vindas de outros países é a mais antiga e tradicional do município, teve início na Igreja da Matriz, atualmente conhecida como Basílica.

As romarias continuam sendo a maior atividade religiosa e cultural do lugar.

A romaria de finados é considerada a segunda do município, é realizada no mês de novembro em homenagem ao fundador da cidade, Padre Cícero Romão Batista, os fiéis se concentram em maior parte na capela de Nossa Senhora do Perpétuo Socorro onde se encontram os restos mortais do Padre Cícero no interior daquela Igreja, recebeu o nome de romaria da esperança, denominação dada pela influência do Trabalho dos Capuchinhos Franciscanos.

A festa de Nossa Senhora das candeias comemorada com procissões conduzindo tochas acesas (velas) com grandes quantidades de pessoas, sendo romeiros vindo dos estados do Nordeste e pelo povo da cidade cantando o hino "Valeime, meu Padim Cíço e a mãe de Deus das Candeias".

Os devotos saem de um ponto determinado percorrendo diversas ruas tendo como ponto de chegada da procissão a Basílica de Nossa Senhora das Dores.

Existem também a celebração do ciclo natalino e aqueles do aniversário da "despedida" e do nascimento do Padre Cícero. São milhões os devotos vindos de todo o Nordeste principalmente dos estados de Pernambuco, Alagoas, Piauí, Sergipe, Paraíba e Bahia, fazem a peregrinação até Juazeiro do Norte, vindo de caminhões, ônibus, alguns paude-arara adaptados para o transporte de pessoas. São grandes as atividades religiosas, o mesmo é considerado o segundo centro de religiosidade popular do Brasil. Segundo a história cerca de dois milhões ou mais de romeiros visitam a cidade cada ano, perdendo apenas para a romaria de Aparecida do Norte no Estado de São Paulo. 
Os setores que mais se destacam próximo ao Padre Cícero são os culturais e os econômicos.

Na rede do município existem três museus que são a casa do museu do Padre Cícero, o Museu Vivo do Padre Cícero e o que está situado no Memorial Padre Cícero. Existem vários locais que dizem casas de supostos milagres onde os devotos depositam peças que representam as promessas, os milagres que os mesmos acreditam através da fé que tenham alcançado.

As romarias fortalecem o comercio principalmente na venda de produtos como lembranças, velas, comidas, principalmente nos ranchos, hotéis, hospedarias, entre outros.

Durante as visitas, o Horto se tornou o lugar de maior destaque, sendo mais visitados no período da manhã, durante a madrugada muitos saem em penitência caminhando ao Horto onde seguem muitas vezes ao Santo Sepulcro, cerca de 6 km de distância.

Os romeiros seguem rumo ao Santo Sepulcro onde caminha admirando a natureza, rezando e fazendo penitências.

A romaria tem como principal ponto de visita a estátua do Padre Cícero, e as lembranças sem esquecer da importância do inesquecível patriarca fundador do Juazeiro e os desafios que o mesmo viveu durante tantos anos.

No Horto ainda são encontradas testemunhas edificados como restos do muro de batalha da chamada Sedição de Juazeiro de 1914, casas e ermidas de beatos e uma capela anexa que nos dias de hoje é conhecido como Museu Vivo do Padre Cícero.

O muro da resistência constituído em 1914 com ajuda de devotos de pessoas de Juazeiro e dos romeiros do Nordeste como forma de defender Juazeiro das tropas de Franco Rabelo, o muro ficou conhecido como Sedição de Juazeiro do Norte (ou muro de resistência, ou círculo da mãe de Deus) o importante é que alcançaram êxito e hoje o Juazeiro é uma das cidades que mais cresce no Ceará.

\section{Aspecto Geológico}

$\mathrm{Na}$ região do Cariri cearense encontram-se as rochas mais antigas que se originou no interior do Ceará, há aproximadamente 650 milhões de anos essas rochas são substrato das 
rochas sedimentares que constituem a bacia do Araripe, tendo grande parte dos seus sedimentos.

Sabe-se que as rochas granias como as que constituem o substrato rochoso do Geossítio Colina do Horto, são formados devido o lento resfriamento do magma alguns milhões de anos, através de vimentos das placas tectônicas e pela destruição por erosão das rochas que estavam por cima, uma vez na superfície, estas ficam expostas aos processos de erosão e alteração, dando origem aos grandes blocos de granitos, facilmente visualizados no Santo Sepulcro.

Segundo Cunha e Guerra (1996), o solo é conceituado como parte fundamental que integra o meio ambiente e que merece uma observação mais cuidadosa na sua composição, já que o mesmo é influenciado na formação do relevo, além disso eles denunciam as características, os processos e os mecanismos que atuam na sua formação.

Diogenes e Rocha afirmam que a educação ambiental tem propósito pautado na reversão da crise ambiental.

A "educação ambiental" foi desde o início conceitualmente, como estratégia, tentativa a reversão de afamada "crise ambiental", mas essa crise, seja ela ambiental ou não, é uma crise de relação que desencadearam juntamente com a evolução da humanidade.

Saber usar como instrumento a construção do saber no contexto da educação ambiental é tarefa do educador. Nesse sentido é de grande importância a influência da educação ambiental na Sociedade. (JACOBI, 2003)

O fato de vivermos em sociedade, de entrarmos em constante interação com os outros, afim de compreendermos a nós mesmos e a tudo que está a nossa volta, faz parte de um longo processo de internalização de formas culturais. Ao mesmo tempo que originam. Também modificam nossos comportamentos, nossas concepções, nossa forma de tratar as pessoas, de emitir opiniões, em fim de proceder, decifrar, desvendar, explicar e dar sentido ao mundo em que estamos inseridos.

Deve-se pensar na coletividade, trabalhar a favor da cidadania pois a mesma é praticada por indivíduos cidadãos que se importam com as condições que as pessoas e com o meio ambiente, e com as condições do lugar em que vivem, procurando sempre participar de organizações que trabalhem pelo bem comum. Que o cidadão tome partido e saiba dos 
problemas ambientais que afetam a sociedade e interfira em sua vida e na de cada pessoa e aja pelo bem de todos.

Quando o homem compreender sua realidade, pode levantar hipóteses sobre o desafio dessa realidade e procurar soluções e assim pode transforma-la e com seu trabalho pode criar um próprio: seu eu e suas circunstâncias. (FREIRE, 2002, p.30)

A educação para a cidadania requer as questões socioambientais seja apresentada para a aprendizagem e a reflexão dos cidadãos, abrindo um espaço mais democrático para as discussões, buscando um tratamento didático e transversal. A transversalidade propõe a articulação entre o tema e as reflexões.

O homem se torna sujeito do processo quando procura em qualquer circunstância pensar, refletir e de forma crítica, que seja individual ou coletiva, ativa e participativa, agir contribuir para a educação da cidadania, preservando, zelando e respeitando o meio ambiente em que vive e procurando uma melhor qualidade de vida para o ser humano, hoje e sempre.

\section{Conclusões}

Pôde-se constatar através deste artigo que cada vez mais acentua o interesse de conhecer melhor a natureza através da colina do horto, observando o meio ambiente, procurando por meio da leitura agir em defesa do mesmo, aprendendo cada vez mais como melhorar sua qualidade de vida.

Este Artigo oferece uma panorâmica, abordando vários temas em relação ao assunto supracitado, chamando atenção para preservação, e conservação da Colina do Horto, como também, da Estátua do Padre Cícero, Santo Sepulcro entre outros, e por meio das ilustrações nelas contidas, o leitor possa conhecer melhor a sua história e seu papel e de sua contribuição em relação a natureza e a importância do conhecimento ambiental, para melhorar a vida do ser humano no município, preservando os recursos naturais e respeitando as transformações que nela existam sem interferência humana, deixando acontecer de forma natural. 
Id on Line Revista Multidisciplinar e de Psicoloqia

Id on Line Multidisciplinary Journal and Psycology

\section{Agradecimentos}

A Prefeitura Municipal de Juazeiro do Norte pela disponibilização das imagens utilizadas neste estudo.

\section{Referências}

AYRARGUES, Philippe; LIMA, Gustavo F. C. Mapeando as Macrotendências Político Pedagógicas de Educação Ambiental Contemporânea no Brasil. VI Encontro "pesquisa em educação ambiental e após - Graduação no Brasil. Ribeirão Preto, setembro de 2011.

DELA CAVA, Relf. Milagre em Juazeiro. Rio de Janeiro: Paz e Terra, 2003

FREIRE, Paulo. A importância do Ato de Ler. 27ed. São Paulo, Cortez, 1992

JACOBI, P.R. Educação Ambiental, Cidadania e Sustentabilidade. Caderno de pesquisas (Fundação Carlos Chagas), São Paulo, 118 p. 189-205, 2003

LIMA JÚNIOR, F. de O. Geopark Araripe. Histórias da Terra, do Meio Ambiente e da Cultura. Apresentação. Universidade Regional do Cariri. Crato, Ceará, Sd.

PITOMBO, João P. Venerado no Nordeste, Padre Cícero recebe perdão de Igreja Católica. Disponível em: http://www1.folha.uol.com.br/poder/2015/12/1718807-veneradono-nordeste-padre-cicero-recebe-perdao-da-igreja-catolica.shtml. Acesso em 12.07.2016.

Como citar este artigo (Formato ABNT):

COSTA, F.I.O.B.; BESERRA, T.M.A.C. Colina do Horto: observando e aprendendo com o meio ambiente Id on Line Revista Multidisciplinar e de Psicologia, Set-Out de 2016, vol.10, n.31, Supl 2, p. 236-249. ISSN 1981-1179.

Recebido: 16/09/2016

Aceito: 25/09/2016 